\title{
Review
}

Journal of Innate

Immunity
J Innate Immun 2011;3:355-364

DOI: $\underline{10.1159 / 000325465}$
Received: December 8, 2010

Accepted after revision: February 10, 2011

Published online: April 18, 2011

\section{Natural Killer Cells and Solid Tumors}

\author{
Ana Stojanovic Adelheid Cerwenka \\ Innate Immunity, German Cancer Research Center, Heidelberg, Germany
}

\section{Key Words}

Natural killer cells • Tumor immunology •

Tumor microenvironment

\begin{abstract}
Natural killer (NK) cells play an important role in the innate immune response against cancer, in particular in the elimination of tumor metastases and small tumors. NK cell-mediated control of large solid tumors is usually not efficient, although tumors often express high amounts of activating ligands and low levels of inhibitory ligands, such as MHC class I. Thus, we assume that these tumors might be good targets for NK cell-mediated attack. In vitro, NK cells directly kill tumor cells and release soluble factors that affect both innate and adaptive immune responses. To date, in vivo NK cell activation during tumor progression, the influence of the tumor microenvironment on NK cells, and the mechanisms that interfere with their effector function in cancer patients are not completely understood. This review summarizes our current knowledge of NK cells in solid tumors. We will discuss the impact of novel insights into NK cell responses against tumors on the design of NK cell-based therapies.
\end{abstract}

Copyright $\odot 2011$ S. Karger AG, Basel

\section{Introduction}

With the exception of certain hematological malignancies, cellular transformation events often result in the formation of a solid primary tumor mass that can lead to metastases. The most frequent cancers in industrialized countries are solid tumors derived from epithelial tissues, such as breast, lung, prostate or colorectal carcinoma. The prognosis of patients suffering from these carcinomas is still very poor. Protocols for the treatment of solid tumors mostly rely on the surgical removal of the primary tumor mass. Advanced stages of cancer, however, preclude surgical resection. Reduction of the tumor mass is required, which is mainly achieved by irradiation or chemotherapy, both of which are characterized by severe side effects.

During tumor formation, malignant cells and infiltrating immune cells constantly interact with each other and shape the tumor microenvironment. In the majority of studies, high numbers of immune cells, such as natural killer (NK) cells or $\mathrm{CD}^{+} \mathrm{T}$ cells, infiltrating the tumors correlate with an improved prognosis for cancer patients $[1,2]$. Thus, therapeutic strategies aiming at increasing the numbers of these cells in tumors might be beneficial

\begin{tabular}{ll}
\hline KARGER & (c) 2011 S. Karger AG, Basel \\
$1662-811 X / 11 / 0034-0355 \$ 38.00 / 0$ \\
Fax +4161306 1234 \\
$\begin{array}{l}\text { E-Mail karger@karger.ch } \\
\text { www.karger.com }\end{array}$ & $\begin{array}{l}\text { Accessible online at: } \\
\text { www.karger.com/jin }\end{array}$
\end{tabular}

Dr. Adelheid Cerwenka

Innate Immunity (D080), German Cancer Research Center Im Neuenheimer Feld 280 DE-69117 Heidelberg (Germany)

Tel. +496221 42 4480, E-Mail a.cerwenka@dkfz.de 
to improve current immunotherapy protocols. NK cells were initially described as innate immune effector cells with the capacity to destroy tumor cells without prior sensitization [3, 4]. More recently, it has become clear that although resting NK cells mount certain responses [5], the activation of NK cells, such as by 'priming' with dendritic cells (DCs) [6], is required to exploit their full effector potential. The parallel inhibition of mechanisms counteracting NK cell activation should facilitate effective NK cell responses. A crucial role of NK cells in the elimination of hematological malignancies, tumor metastases and small tumors has been recognized [7, 8]. However, the NK cell-mediated response against established solid tumors at late stages of tumor progression remains largely ineffective.

\section{The Importance of NK Cells during Antitumor Immune Responses}

Individuals with impaired NK cell function, as assessed by the lysis of K562 cells, display an increased risk of developing cancer [9]. Moreover, studies in experimental tumor models demonstrated that NK cells were involved in the control of the certain tumors, including spontaneously arising, transplanted or carcinogen-induced malignancies. In the majority of these studies, NK cell depletion was performed with anti-NK1.1 or antiasialo-GM1 mAbs. This experimental approach leaves the possibility that the depleting mAbs affected other cell populations, such as NKT or myeloid cells, as well. Several reports indicated that in mice deficient for activating NK cell receptors, such as NKG2D or NKp46, tumor growth was enhanced $[10,11]$. Furthermore, increased levels of NKG2D ligands and NKp46 ligands were expressed by tumors arising in NKG2D or NKp46-deficient mice, respectively $[10,12]$. These results suggest that NKG2D and NKp46 are involved not only in tumor immune surveillance but also in immunoediting and tumor escape. Accelerated tumor progression was also observed in mice lacking molecules involved in NK cell effector responses, including perforin, TRAIL and IFN- $\gamma$. However, these molecules are expressed not only by NK cells but also by other immune cells, and in most studies the relative contribution of NK cells remained poorly defined.

The report of selective expression of NKp46 by NK cells prompted the generation of improved tools for the investigation of NK cell responses [13]. Mice carrying the NKp46 promoter linked to the diphtheria toxin receptor were generated, in which most NK cells are depleted by diphtheria toxin application. Moreover, crossing mice carrying the NKp46 promoter linked to Cre recombinase with mice with loxP site-flanked genes resulted in mouse strains that allow the investigation of the deficiency of defined molecules in $\mathrm{NKp} 46^{+}$cells [14]. Importantly, NKp46 is more broadly expressed as previously anticipated. Recently, it was reported that NKp46 is expressed on lymphoid tissue inducer-like cells involved in the rejection of IL-12-transfected subcutaneously applied B16 melanoma [15]. This rejection was abrogated in mice lacking the transcription factor ROR $\gamma \mathrm{t}$, but was functional in Rag1-, IL-15R $\alpha-$, IL-22-, IL-17 $\alpha-$, IFN- $\gamma-$, IFN- $\gamma$ R1and perforin-deficient mice. Furthermore, a cell population in mouse intestinal mucosa, closely related to lymphoid tissue inducer cells, was recently described to express NKp46 [16]. These cells depend on ROR $\gamma \mathrm{t}$, produce IL-22 and lack 'natural cytotoxicity' in vitro that is the typical feature of classical NK cells. Thus, certain NKp46-expressing subpopulations might have distinct developmental requirements and functional properties compared to classical NK cells.

So far, most studies investigating NK cell responses to tumors were performed in tumor models using transplanted tumor cell lines. In these models, inoculation of tumor cells exposes NK cells to nonphysiologically high numbers of malignant cells. Furthermore, transplanted tumor cell lines arose and/or were passaged in mice. Thus, these cell lines were shaped by the presence of the immune system and often acquired a low immunogenic phenotype to escape from immunosurveillance. In tumor models of transplanted tumor cells, the importance of NK cells for tumor rejection depends on the numbers of injected tumor cells. The MHC class I-deficient lymphoma cell line RMA-S is rejected when injected at relatively low cell numbers, whereas high cell numbers lead to continuous tumor growth. Depletion of NK1.1 $1^{+}$cells resulted in accelerated tumor growth indicating that tumor growth was controlled by NK1.1 $1^{+}$cells [17].

Mouse models of spontaneously arising tumors allow a more accurate analysis of the dynamics and kinetics of NK cell antitumor responses. In these models, NK cells face small numbers of transformed cells in the early phase of tumor development and tumor progression more closely resembles the development of solid human tumors. Although studies in mouse models of transplanted tumor cell lines provide insight into the general mechanisms of NK cell responses against tumors, it is important to validate novel results in mouse models of spontaneous tumor formation. 
Fig. 1. CD $56^{\text {bright }} \mathrm{NK}$ cells comprise $5-10 \%$ of peripheral blood NK cells but preferentially accumulate in the tumor tissue. Their increased frequency detected in various human cancers can be the consequence of different processes. CD56 $6^{\text {bright }}$ NK cells can be selectively recruited to the tumor site due to their expression of chemokine receptors, e.g. CXCR3. Most of the recruited NK cells, however, reside in the tumor stroma. In addition, CD56 $6^{\text {bright }}$ cells might display increased proliferation and/ or survival within tumor tissue as compared to the CD56 ${ }^{\mathrm{dim}}$ subset.

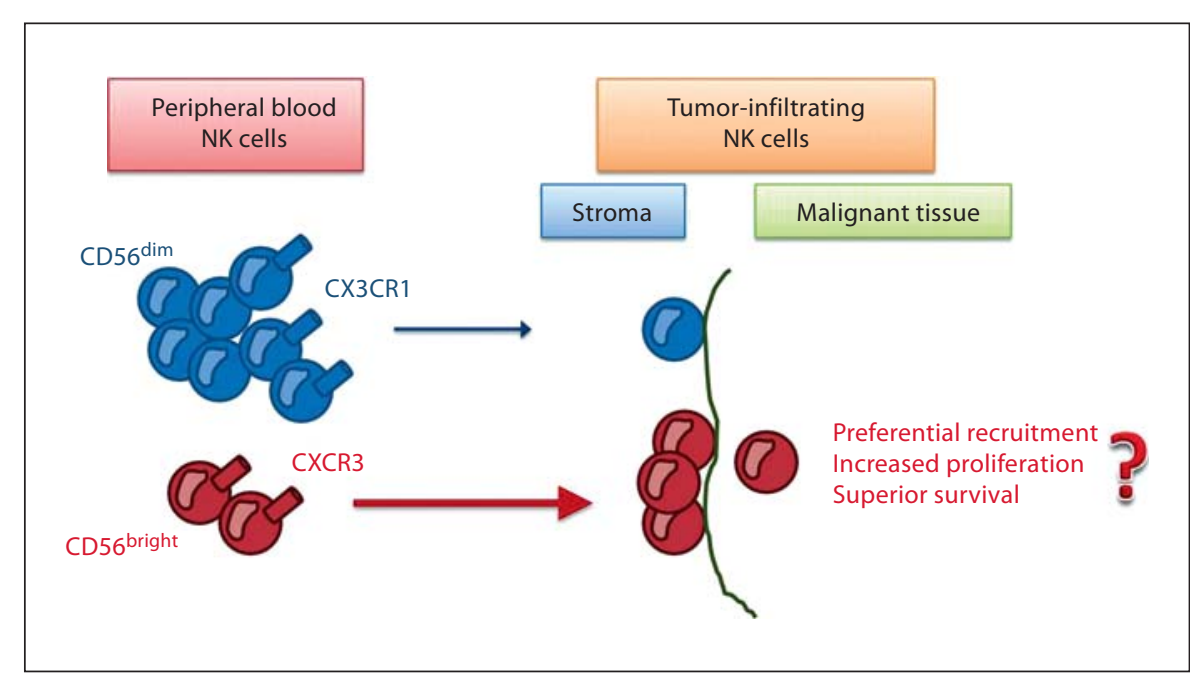

\section{Examples of NK Cell-Based Immunotherapy}

Currently, several approaches that exploit NK cells for antitumor therapy exist. Upon haploidentical stem cell transplantation of patients suffering from acute myeloid leukemia, $>50 \%$ of patients who received grafts with donor-recipient killer immunoglobulin receptor (KIR)HLA class I mismatch survived longer than 5 years as compared to $<5 \%$ in the absence of the mismatch [18]. In vitro studies demonstrated that most acute myeloid leukemia blasts expressed ligands for the activating NK cell receptors DNAM-1, NKp30 and NKp46, and were susceptible to NK cell lysis [19]. Several treatments of solid tumors involve NK cells as well [20]. NK cells are implicated in the response to Mycobacterium bovis bacillus Calmette-Guerin treatment of bladder cancer and tyrosine kinase inhibitor imatinib mesylate (Gleevec) treatment of gastrointestinal stromal tumors. In addition, the efficiency of antibody-based therapy partially relies on NK cell-mediated antibody-dependent cellular cytotoxicity. NK cells were also recognized as effectors in DCbased immunotherapy. During antitumor immune responses, NK cells are an important source of IFN- $\gamma$ that has multiple antitumor effector functions, including the inhibition of angiogenesis and tumor vascularization [21]. Importantly, regulatory functions of NK cells, such as the secretion of the immunosuppressive cytokine TGF- $\beta$, elimination of antigen-presenting cells and direct lysis of activated $\mathrm{T}$ cells [22], were also reported. Thus, protocols of cancer immunotherapy should consider possible adverse effects of NK cells in antitumor immunity.

NK Cells and Solid Tumors

\section{NK Cell Accumulation in the Tumor Tissue}

NK cells are detected in solid tumors in both mouse models and cancer patients. In lung, gastric or colorectal cancer patients, a high number of NK cells in the tumor tissue correlated with an improved prognosis [2, 23, 24]. In gastric carcinoma, high amounts of infiltrating NK cells correlated with the reduced depth of tumor invasion, lower numbers of metastases in the lymph nodes and improved clinical outcome. In these studies, NK cells were identified by the expression of CD57. CD57 defines only a subset of NK cells and comprises a small subpopulation of T cells as well. Recent studies demonstrated that CD57 was preferentially expressed by CD $56^{\text {dim }} \mathrm{NK}$ cells and correlated with a high expression of inhibitory MHC class I-specific KIRs; low expression of the activating receptors NKp30, NKp46 and NKG2D; low expression of the cytokine receptors IL-2R $\beta$ and IL-12R $\beta$; and reduced proliferative capacity $[25,26]$. Moreover, $\mathrm{CD} 57^{+} \mathrm{NK}$ cells were potent IFN- $\gamma$ producers and showed high lytic capacity when stimulated via CD16. These observations suggest that tumor tissue infiltration by $\mathrm{CD} 56^{\mathrm{dim}} \mathrm{CD} 57^{+}$ NK cells might be beneficial for effective antitumor responses. It will be important to revisit these studies using markers expressed on all NK cells such as NKp46.

Several studies indicated that tumor tissues were preferentially infiltrated by $\mathrm{CD} 56^{\text {bright }} \mathrm{CD} 16^{-} \mathrm{NK}$ cells $[27$, 28]. Figure 1 illustrates several mechanisms that might contribute to the increased frequency of $\mathrm{CD} 56^{\text {bright }} \mathrm{CD} 16^{-}$ NK cells in tumors. It is currently not known whether CD56 ${ }^{\text {bright }}$ and CD56 ${ }^{\text {dim }}$ subsets are differentially recruited to the tumor site and/or whether their phenotype

J Innate Immun 2011;3:355-364 
is changed by the tumor microenvironment. Elevated numbers of $\mathrm{CD} 56^{\text {bright }} \mathrm{NK}$ cells in the tumor might be a consequence of their increased proliferation and/or survival. In this respect, it was demonstrated that CD56 bright NK cells display improved survival under conditions of oxidative stress, which is often present within tumor tissue [29].

In most cases, the frequency of NK cells among total tumor-infiltrating immune cells is low, resulting in a low ratio between NK cells and tumor cells. In addition, as reported for colon and lung cancer, NK cells are often not located in direct contact with tumor cells, but rather in the proximity of the blood vessels within the stroma [30, 31]. Application of IL-2, IL-12, IL-21, IFN- $\alpha$, CpG or therapeutic $\mathrm{mAbs}$, was shown to increase numbers and/or activity of peripheral blood NK cells in cancer patients [20]. Increased NK cell numbers in the blood might be beneficial for the elimination of hematological malignancies or disseminated tumor cells. However, based on the low overall response seen in most of the treated patients with solid tumors, we assume that efficient targeting of these tumors by NK cells should aim at an increase of their numbers and activation in the tumor tissue.

NK cells arrive at the tumor site via the blood, extravasate through vessels and migrate through the tumor tissue. These processes depend on molecules that mediate cellcell and cell-extracellular matrix interactions, the modulation of extracellular matrix components and on chemokines and chemokine receptors expressed by NK cells [32]. Receptors that mediate NK cell migration to inflamed tissues such as CCR2, CCR5, CXCR3 and CX3CR1 allow NK cells to respond to a broad spectrum of inflammatory chemokines [33]. CXCR3 and CX3CR1 were implicated in NK cell recruitment to the tumor tissue. These receptors are differentially expressed by NK cell subsets. We observed that tumors of different origin injected subcutaneously in congenic mice were mainly infiltrated by the $\mathrm{CD}_{11} \mathrm{~b}^{+} \mathrm{CD} 27^{\text {high }} \mathrm{NK}$ cell subset [our unpubl. observations] that is considered to be the mouse equivalent of the human $\mathrm{CD} 56^{\text {bright }}$ population. $\mathrm{CD} 11 \mathrm{~b}^{+} \mathrm{CD} 27^{\text {high }} \mathrm{NK}$ cells express CXCR3 and are attracted to the tumor in a CXCR3-dependent manner [34]. Similarly, in humans, the CD56 ${ }^{\text {bright }}$ NK cell subset expresses CXCR3 at high levels that might be responsible for their preferential accumulation in tumors. In vitro, mouse $\mathrm{CD} 11 \mathrm{~b}^{+} \mathrm{CD} 27^{\text {high }}$ NK cells display superior responses compared to the CD27 low subset [35]. However, the functional properties of human NK cell subpopulations are more complex. Traditionally, CD56 ${ }^{\mathrm{dim}} \mathrm{NK}$ cells were classified as 'killers' whereas $\mathrm{CD} 56^{\text {bright }}$ were considered as 'cytokine producers'. More recent studies revealed that NK cell responses were dependent on the type of activation and that both subsets performed both functions when triggered appropriately [36]. In this respect, we assume that the activation stimuli and the tumor microenvironment determine the type of response exerted by tumor-infiltrating NK cells. To date, it is still not clear, which NK cell subpopulation is most effective in controlling tumor growth in vivo.

Several studies have investigated whether tumors that are susceptible to NK cell lysis were infiltrated by higher numbers of NK cells. More NK cells were shown to accumulate in the peritoneum of mice inoculated with MHC class I-deficient RMA-S compared to MHC class I-sufficient RMA cells [37]. Furthermore, higher numbers of NK cells were detected within NK cell-susceptible RMA-Rae-1 tumors as compared to NK cell-resistant RMA tumors [38]. These observations indicate that mouse NK cells preferentially accumulate in tumors susceptible to their lysis. However, in cancer patients different results were reported. For example, Sandel et al. [31] showed that although the majority of colorectal carcinoma displayed low or absent MHC class I expression and levels of immune cell infiltration were relatively high, attracted cells mostly resided in the tumor stroma. Loss of MHC class I on tumor cells positively correlated with $\mathrm{CD}^{+} \mathrm{T}$ cell infiltration and inversely correlated with NK cell infiltration in the tumors. These data would imply that certain tumors might selectively exclude cells that harm them. However, loss of MHC class I correlated with fewer metastases, suggesting that in those patients NK cells might be involved in the clearance of metastatic cells with diminished MHC class I expression [39].

\section{NK Cells within the Tumor Microenvironment}

Impaired effector functions of different immune cells isolated from tumor tissue were reported. Unresponsive tumor-specific T cells were isolated from various human tumors [40]. These cells can recover functional competence upon ex vivo stimulation, indicating that the process is reversible. The mechanisms underlying impaired $\mathrm{T}$ cell activation within the tumor tissue include the alterations in the proximal TCR signaling machinery characterized by decreased expression of $\mathrm{CD} 3 \zeta$ and the tyrosine kinases Lck and Fyn. Impaired expression of NF- $\kappa$ B family proteins correlates with decreased Th1 cytokine production and CTL function. In addition, conjugate formation of tumor-infiltrating $\mathrm{CD}^{+} \mathrm{T}$ cells with tumor 
cells ex vivo is impaired due to the defective expression and activation of adhesion molecules.

Several studies have investigated numbers and functionality of NK cells in tumor patients. In most studies, an impaired function of NK cells isolated from tumors was reported and an association of impaired NK cell activity and cancer progression was described [41, 42]. Figure 2 summarizes suppressive factors that inhibit NK cell activation in the tumors. Decreased NK cell responses have been detected in patients with lung and liver cancer as well as in melanoma, chronic myeloid and acute lymphoid and myeloid leukemia [43-47]. Another study reported that in patients with metastatic disease, cytotoxic responses of peripheral blood cells against K562 cells were reduced, whereas cancer patients without metastases mounted responses comparable to healthy donors [48].

In mouse models of subcutaneously injected melanoma, breast or colon carcinoma cells, NK cell differentiation to the final maturation stage in the bone marrow was impaired during the late stages of tumor progression leading to accumulation of immature NK cells [49]. In parallel, spleen NK cells from tumor-bearing mice did not show defects in cytotoxicity, whereas IFN- $\gamma$ production was reduced in response to PMA/Ionomycin, but not to IL-12 stimulation. Recently, Brenner et al. [50] reported that in a transgenic mouse model of spontaneously arising lymphoma, effector functions of tumor-infiltrating NK cells became paralyzed during tumor progression.

Similar to T cells, different mechanisms account for the NK cell impairment in cancer patients. NK cells isolated from ascetic fluid of ovarian carcinoma patients expressed decreased levels of CD3 $\zeta$, FceRI $\gamma$ and Lck compared to cells from peripheral blood, which correlated with their reduced ability to produce IFN- $\gamma$ upon IL-2 stimulation [51]. Tumor-infiltrating NK cells in ovarian cancer patients that expressed low levels of $\mathrm{CD} 3 \zeta$ produced less IFN- $\gamma$, IL-2 and IL-4, but more IL-10, compared to peripheral blood NK cells [52]. Moreover, we observed that mRNA levels of several key components of the signaling machinery downstream of activating NK cell receptors, such as Lck, PI3K, PLC $\gamma$ and Vav, were decreased in NK cells infiltrating mouse lymphoma compared to peripheral blood NK cells [our unpubl. observations].

In most studies that investigate NK cell function from cancer patients, NK cells are isolated from peripheral blood due to the good accessibility of blood samples and tested against targets such as K562. It has to be considered

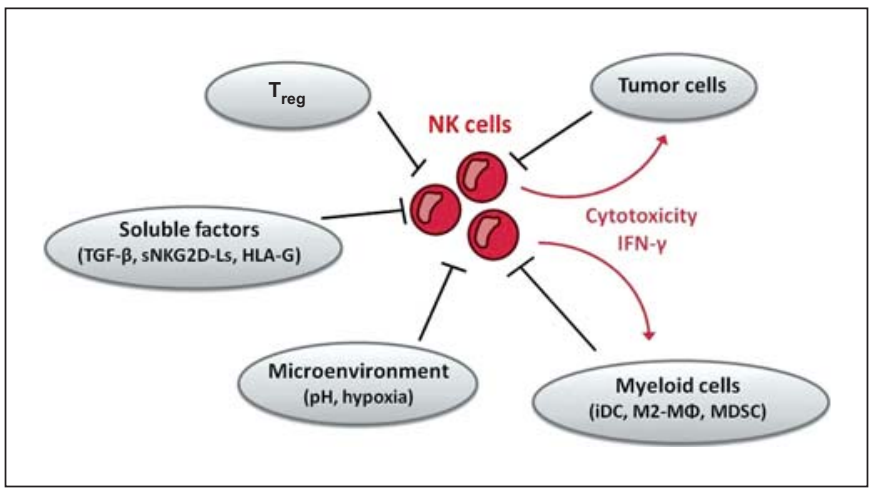

Fig. 2. Suppressive factors in the tumor microenvironment. Various factors in the tumor microenvironment can suppress NK cell effector responses. These include low $\mathrm{pH}$ and oxygen levels, soluble molecules, such as TGF- $\beta$, HLA-G or NKG2D ligands, or suppressive cell populations, including $\mathrm{T}_{\text {reg }}$ and MDSCs. NK cell dysfunction is partially caused by downregulation of activating receptors and downstream signaling molecules that impair target cell recognition and NK cell activation. NK cells can prevent accumulation of cells that support tumor progression, e.g. via direct lysis of immature DCs or prevention of M2-macrophage polarization by IFN- $\gamma$ production.

that peripheral blood NK cells might display many differences with regards to phenotype and function compared to NK cells isolated from the tumor tissue. To correlate NK cell responses after certain treatments with the prognosis of tumor patients, it is important (whenever possible) to investigate the effector potential of tumor-infiltrating NK cells rather than the potential of peripheral blood NK cells.

\section{NK Cell-Mediated Target Recognition in the Tumor Microenvironment}

Activating receptors expressed by NK cells, including NKG2D, NCRs and DNAM-1, have been implicated in direct recognition of cancer cells. The control of tumor growth mediated by the activating receptor NKG2D operates mainly through perforin-dependent cytotoxicity and can be enhanced by treatment with IL-2 and IL-12 [53]. NKG2D ligands are expressed on the surface of many tumor cell lines and primary tumor cells, but rarely by healthy cells [54]. Induction of NKG2D ligands via the activation of the DNA damage pathway by certain chemotherapeutic drugs or ionizing radiation can increase the visibility of tumors to NK cells [55]. Similarly, DNA damage pathway activation increases the expres- 
sion of the poliovirus receptor CD155 and Nectin-2, ligands for activating receptor DNAM-1 [56]. Efficient recognition of target cells usually involves engagement of more than one activating receptor [57]. The simultaneous blockade of DNAM-1 and NCRs often leads to the complete abrogation of tumor cell lysis. Most NCR ligands expressed on tumor cells are still elusive. It was recently reported that NKp30 binds to BAT3, an intracellular protein that is released upon cell death [58]. In addition, B7H6, a novel member of the B7 protein family expressed by certain tumor cell lines and a subset of primary tumor cells of hematological neoplasias, but not by healthy cells, binds to NKp30 and activates NK cell cytotoxicity [59].

The surface expression of activating NK cell receptors in cancer patients is often reduced on tumor-infiltrating compared to NK cells from peripheral blood [60]. In vitro studies indicated that fibroblasts derived from human melanoma interfered with NK cell cytotoxicity and cytokine production through the decrease of NKp30, NKp44 and DNAM-1 expression [61]. NKG2D cell surface expression was shown to be downregulated upon continuous exposure to its ligands, which also leads to the impaired function of several other activating NK cell receptors [62]. Similarly, DNAM-1 is downregulated upon NK cell exposure to target cells expressing cognate ligands [63]. In cancer patients, NKG2D ligands are often shed from the surface of tumor cells $[64,65]$. Increased levels of soluble NKG2D ligands in serum correlated with the decreased expression of the NKG2D on both $\mathrm{NK}$ and $\mathrm{CD} 4^{+} \mathrm{T}$ cells. Moreover, elevated serum levels of soluble ULBP2 in melanoma patients were associated with disease progression and poor prognosis [66]. Soluble factors such as TGF- $\beta$ and L-kynurenine, a tryptophan catabolite generated by indoleamine 2,3-dioxygenase, also downregulate NKG2D and NKp30 cell surface expression by NK cells $[67,68]$. Our unpublished data suggest that expression of activating NK cell receptors in the tumor microenvironment is also regulated at the transcriptional level and that receptors recognizing tumor cells are preferentially downregulated.

\section{Interplay of NK Cells with Other Immune Cells in the Tumor Tissue}

Within the tumor tissue, multiple cell types with suppressive functions can be detected, including immature DCs, macrophages polarized towards the immunoregulatory M2 phenotype, suppressive myeloid cells and regulatory $\mathrm{T}$ cells $\left(\mathrm{T}_{\text {reg }}\right)$. The number of cytolytic $\mathrm{NK}$ and
$\mathrm{CD}^{+} \mathrm{T}$ cells is low compared to cells that suppress immune responses and support tumor progression. In tumors, NK cells can interact with different types of immune cells affecting the function of both interaction partners. DCs in solid tumors often display an immature phenotype characterized by low expression of costimulatory molecules [69]. The cross-talk of NK cells with DCs leads to DC maturation, but under certain conditions results in the elimination of immature DCs [70]. Tumorassociated macrophages originating from blood monocytes accumulate in the tumor tissue and become reprogrammed in the tumor microenvironment to support tumor progression [71]. They secrete factors that recruit other myeloid cells, support angiogenesis and matrix remodeling, and polarize $\mathrm{T}$ cell differentiation towards Th2 and $\mathrm{T}_{\text {reg. }}$ IFN- $\gamma$ produced by NK cells is a crucial factor to prevent macrophage polarization towards M2 phenotype and induce DC maturation. Thus, NK cells might affect several types of potentially immunosuppressive cells and thereby support the generation of efficient antitumor responses.

Several factors produced within the tumor tissue, such as VEGF, GM-CSF, M-CSF and IL-6, impede normal myelopoiesis and support accumulation of immature myeloid cells in the bone marrow, blood, spleen and tumor of tumor-bearing mice and cancer patients [72]. These cells can suppress $\mathrm{T}$ cell responses and were called 'myeloid-derived suppressor cells' (MDSCs). In mouse models, MDSCs were reported to suppress [73] or promote NK cell responses [74], depending on the tumor model studied. Evidence exists that NK cells eliminate the monocytic subset of MDSCs expressing the NKG2D ligand Rae-1 [74].

Similar to MDSCs, $\mathrm{T}_{\text {reg }}$ accumulate in blood, draining lymph nodes and tumor tissue of cancer patients and tumor-bearing mice. Both active recruitment and in situ proliferation contribute to $\mathrm{T}_{\text {reg }}$ accumulation and are mediated by other suppressive cells in tumors, such as immature DCs and MDSCs. $\mathrm{T}_{\text {reg }}$ control homeostatic proliferation of NK cells in mice as well as their antitumor responses. Moreover, NK cell-mediated rejection of RMA-S-Rae-1 $\beta$ tumors is inhibited by $\mathrm{T}_{\text {reg }}$ [75]. Further reports demonstrated that membrane-bound TGF- $\beta$ was

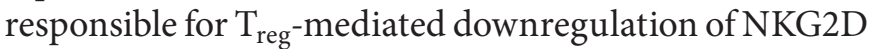
and suppression of IL-12-induced IFN- $\gamma$ production by NK cells [76].

In conclusion, a complex regulatory network of NK cells and other immune cells exists in the tumor tissue. Its therapeutic manipulation will contribute to efficient NK cell activation against tumors. 
Effect of Tumor-Released Soluble Factors on NK Cell Function

Several characteristics of the tumor microenvironment impede effective antitumor immune responses. Low $\mathrm{pH}$ and oxygen concentration prevent the normal function of effector cells, including NK cells [77]. TGF- $\beta$ is an important immunosuppressive factor with broad effects on both tumor and infiltrating immune cells [78]. It attenuates IL-2-induced IFN- $\gamma$ production and lytic activity by NK cells and directly affects the expression of activating receptors. Furthermore, TGF- $\beta$ can indirectly influence NK cell antitumor responses by affecting DC function, by inducing $\mathrm{T}_{\text {reg }}$ or modulating the expression of adhesion molecules by endothelial cells in tumor vessels. Within the tumor microenvironment, TGF- $\beta$ exerts its function mainly by its membrane-bound form presented by $\mathrm{T}_{\text {reg }}$ and MDSCs $[73,76]$.

IL-10 is an important cytokine that can be secreted within the tumor tissue by tumor cells, macrophages, DCs, $\mathrm{B}$ cells and various subsets of $\mathrm{CD} 4^{+}$and $\mathrm{CD} 8^{+} \mathrm{T}$ cells, including $\mathrm{T}_{\text {reg }}$ [79]. IL-10 differentially affects the response of various immune cells. Evidence of both inhibitory and stimulating effects of IL-10 on NK cell target recognition have been reported. In animal tumor models, administration of the IL-10 recombinant protein or IL-10 gene therapy resulted in profound inhibition of tumor growth and metastases, and involvement of NK cells has been suggested [80]. IL-10 exerts a pleiotropic function on various immune cells and tumor cells, and its role in antitumor responses remains unclear.

Several additional soluble factors produced within the tumor microenvironment, including nonclassical HLA molecules (HLA-E, $-F$ and $-G$ ) were shown to affect NK cell function [81]. HLA-G expression on malignant cells is controlled by epigenetic mechanisms, hypoxia and cytokines such as GM-CSF, IFN- $\gamma$, IL-10 and LIF. HLA-G can be transferred by trogocytosis from APCs and tumor cells to T cells and NK cells resulting in $\mathrm{HLA}-\mathrm{G}^{+} \mathrm{T}$ and NK cells with regulatory functions [82]. KIR2DL4 and ILT-2 (LIR-1), two NK cell receptors that mediate distinct responses, recognize HLA-G. Engagement of KIR2DL4 on NK cells by soluble HLA-G results in the induction of proinflammatory and proangiogenic responses [83], whereas HLA-G expressed on the surface of target cells binds to the receptor ILT-2 and leads to NK cell inhibition [84].

We conclude that multiple factors in the tumor microenvironment affect different aspects of NK cell function.
Their manipulation might help to tip the delicate balance between NK cell activation and inhibition in favor of effective NK cell responses against tumors.

\section{Conclusions}

Although certain therapeutic approaches succeeded in increasing NK cell numbers in the peripheral blood of cancer patients and their ex vivo responses, only minor effects on tumor progression were observed [20]. The reasons might be low NK cell numbers detected in the tumor tissue and the distinct nature of tumor-infiltrating NK cells, including their subset distribution, phenotype, potential interactions with other immune cells and the overall influence of the tumor microenvironment on NK cell function. Therefore, additional knowledge has to be gained regarding NK cell recruitment into tumors, their effector functions within the tumor tissue and their regulation by the complex tumor microenvironment. In addition, further attention has to be devoted to the variety of different tumor entities, their differential sensitivity to immune responses and their distinct potential for immune evasion. Thus, profound knowledge about NK cells in tumors and the influence of the tumor microenvironment will open new promising avenues for the development of improved anticancer immunotherapeutic strategies.

\section{Acknowledgements}

We would like to thank Dr. Alexander Rölle for critically reading the manuscript. We would like to apologize to the authors of papers that could not be cited in this review because of space limitations.

References

1 Deschoolmeester V, Baay M, Van Marck E, Weyler J, Vermeulen P, Lardon F, Vermorken JB: Tumor infiltrating lymphocytes: an intriguing player in the survival of colorectal cancer patients. BMC Immunol 2010;11:19.

$\checkmark 2$ Coca S, Perez-Piqueras J, Martinez D, Colmenarejo A, Saez MA, Vallejo C, Martos JA, Moreno M: The prognostic significance of intratumoral natural killer cells in patients with colorectal carcinoma. Cancer 1997;79: 2320-2328.

3 Kiessling R, Klein E, Pross H, Wigzell H: 'Natural' killer cells in the mouse. II. Cytotoxic cells with specificity for mouse Moloney leukemia cells. Characteristics of the killer cell. Eur J Immunol 1975;5:117-121. 
4 Kiessling R, Klein E, Wigzell H: 'Natural' killer cells in the mouse. I. Cytotoxic cells with specificity for mouse Moloney leukemia cells. Specificity and distribution according to genotype. Eur J Immunol 1975;5:112-117.

5 Bryceson YT, March ME, Ljunggren HG, Long EO: Activation, coactivation, and costimulation of resting human natural killer cells. Immunol Rev 2006;214:73-91.

-6 Lucas M, Schachterle W, Oberle K, Aichele P, Diefenbach A: Dendritic cells prime natural killer cells by trans-presenting interleukin 15. Immunity 2007;26:503-517.

7 Ljunggren HG, Malmberg KJ: Prospects for the use of NK cells in immunotherapy of human cancer. Nat Rev Immunol 2007;7:329339.

8 Chan CJ, Andrews DM, Smyth MJ: Can NK cells be a therapeutic target in human cancer? Eur J Immunol 2008;38:2964-2968.

-9 Imai K, Matsuyama S, Miyake S, Suga K, Nakachi K: Natural cytotoxic activity of peripheral-blood lymphocytes and cancer incidence: an 11-year follow-up study of a general population. Lancet 2000;356:1795-1799.

10 Guerra N, Tan YX, Joncker NT, Choy A, Gallardo F, Xiong N, Knoblaugh S, Cado D, Greenberg NM, Raulet DH: NKG2D-deficient mice are defective in tumor surveillance in models of spontaneous malignancy. Immunity 2008;28:571-580.

- 11 Halfteck GG, Elboim M, Gur C, Achdout H, Ghadially H, Mandelboim O: Enhanced in vivo growth of lymphoma tumors in the absence of the NK-activating receptor NKp46/ NCR1. J Immunol 2009;182:2221-2230.

12 Elboim M, Gazit R, Gur C, Ghadially H, Betser-Cohen G, Mandelboim O: Tumor immunoediting by NKp46. J Immunol;184:56375644.

13 Walzer T, Blery M, Chaix J, Fuseri N, Chasson L, Robbins SH, Jaeger S, Andre P, Gauthier L, Daniel L, Chemin K, Morel Y, Dalod M, Imbert J, Pierres M, Moretta A, Romagne F, Vivier E: Identification, activation, and selective in vivo ablation of mouse NK cells via NKp46. Proc Natl Acad Sci USA 2007;104: 3384-3389.

14 Eckelhart E, Warsch W, Zebedin E, Simma O, Stoiber D, Kolbe T, Rulicke T, Mueller M, Casanova E, Sexl V: A novel Ncr1-Cre mouse reveals the essential role of STAT5 for NK cell survival and development. Blood 2010; 117:1565-1573.

15 Eisenring M, vom Berg J, Kristiansen G, Saller E, Becher B: IL-12 initiates tumor rejection via lymphoid tissue-inducer cells bearing the natural cytotoxicity receptor NKp46. Nat Immunol 2010;11:1030-1038.

-16 Colonna M: Interleukin-22-producing natural killer cells and lymphoid tissue inducerlike cells in mucosal immunity. Immunity 2009;31:15-23.

$\checkmark 17$ Ljunggren HG, Karre K: Host resistance directed selectively against $\mathrm{H}$-2-deficient lymphoma variants. Analysis of the mechanism. J Exp Med 1985;162:1745-1759.
18 Ruggeri L, Capanni M, Urbani E, Perruccio K, Shlomchik WD, Tosti A, Posati S, Rogaia D, Frassoni F, Aversa F, Martelli MF, Velardi A: Effectiveness of donor natural killer cell alloreactivity in mismatched hematopoietic transplants. Science 2002;295:2097-2100.

19 Moretta L, Locatelli F, Pende D, Mingari MC, Moretta A: Natural killer alloeffector responses in haploidentical hemopoietic stem cell transplantation to treat high-risk leukemias. Tissue Antigens 2010;75:103109.

20 Terme M, Ullrich E, Delahaye NF, Chaput N, Zitvogel L: Natural killer cell-directed therapies: moving from unexpected results to successful strategies. Nat Immunol 2008;9:486494.

21 Qin Z, Blankenstein T: CD4+ T cell - mediated tumor rejection involves inhibition of angiogenesis that is dependent on IFN gamma receptor expression by nonhematopoietic cells. Immunity 2000;12:677-686.

22 Rabinovich BA, Li J, Shannon J, Hurren R, Chalupny J, Cosman D, Miller RG: Activated, but not resting, $\mathrm{T}$ cells can be recognized and killed by syngeneic NK cells. J Immunol 2003;170:3572-3576.

23 Ishigami S, Natsugoe S, Tokuda K, Nakajo A, Che X, Iwashige H, Aridome K, Hokita S, Aikou T: Prognostic value of intratumoral natural killer cells in gastric carcinoma. Cancer 2000;88:577-583.

24 Villegas FR, Coca S, Villarrubia VG, Jimenez R, Chillon MJ, Jareno J, Zuil M, Callol L: Prognostic significance of tumor infiltrating natural killer cells subset CD57 in patients with squamous cell lung cancer. Lung Cancer 2002;35:23-28.

25 Bjorkstrom NK, Riese P, Heuts F, Andersson $\mathrm{S}$, Fauriat C, Ivarsson MA, Bjorklund AT, Flodstrom-Tullberg M, Michaelsson J, Rottenberg ME, Guzman CA, Ljunggren HG, Malmberg KJ: Expression patterns of NKG2A, KIR, and CD57 define a process of CD56dim NK cell differentiation uncoupled from NK cell education. Blood 2010;116: 3853-3864.

26 Lopez-Verges S, Milush JM, Pandey S, York VA, Arakawa-Hoyt J, Pircher H, Norris PJ, Nixon DF, Lanier LL: CD57 defines a functionally distinct population of mature NK cells in the human CD56dimCD16+ NK cell subset. Blood 2010;116:3865-3874.

27 Textor S, Durst M, Jansen L, Accardi R, Tommasino M, Trunk MJ, Porgador A, Watzl C, Gissmann L, Cerwenka A: Activating NK cell receptor ligands are differentially expressed during progression to cervical cancer. Int J Cancer 2008;123:2343-2353.

28 Schleypen JS, Baur N, Kammerer R, Nelson PJ, Rohrmann K, Grone EF, Hohenfellner M, Haferkamp A, Pohla H, Schendel DJ, Falk CS, Noessner E: Cytotoxic markers and frequency predict functional capacity of natural killer cells infiltrating renal cell carcinoma. Clin Cancer Res 2006;12:718-725.
29 Harlin H, Hanson M, Johansson CC, Sakurai D, Poschke I, Norell H, Malmberg KJ, Kiessling R: The CD16- CD56(bright) NK cell subset is resistant to reactive oxygen species produced by activated granulocytes and has higher antioxidative capacity than the CD16+ CD56(dim) subset. J Immunol 2007; 179:4513-4519.

30 Esendagli G, Bruderek K, Goldmann T, Busche A, Branscheid D, Vollmer E, Brandau $S$ : Malignant and non-malignant lung tissue areas are differentially populated by natural killer cells and regulatory $\mathrm{T}$ cells in nonsmall cell lung cancer. Lung Cancer 2008;59: $32-40$.

- 31 Sandel MH, Speetjens FM, Menon AG, Albertsson PA, Basse PH, Hokland M, Nagelkerke JF, Tollenaar RA, van de Velde CJ, Kuppen PJ: Natural killer cells infiltrating colorectal cancer and MHC class I expression. Mol Immunol 2005;42:541-546.

32 Albertsson PA, Basse PH, Hokland M, Goldfarb RH, Nagelkerke JF, Nannmark U, Kuppen PJ: NK cells and the tumour microenvironment: implications for NK-cell function and anti-tumour activity. Trends Immunol 2003;24:603-609.

33 Gregoire C, Chasson L, Luci C, Tomasello E, Geissmann F, Vivier E, Walzer T: The trafficking of natural killer cells. Immunol Rev 2007;220:169-182.

34 Wendel M, Galani IE, Suri-Payer E, Cerwenka A: Natural killer cell accumulation in tumors is dependent on IFN-gamma and CXCR3 ligands. Cancer Res 2008;68:84378445.

35 Hayakawa Y, Smyth MJ: Cd27 dissects mature NK cells into two subsets with distinct responsiveness and migratory capacity. J Immunol 2006;176:1517-1524.

36 Fauriat C, Long EO, Ljunggren HG, Bryceson YT: Regulation of human NK-cell cytokine and chemokine production by target cell recognition. Blood;115:2167-2176.

37 Glas R, Franksson L, Une C, Eloranta ML, Ohlen C, Orn A, Karre K: Recruitment and activation of natural killer (NK) cells in vivo determined by the target cell phenotype. an adaptive component of NK cell-mediated responses. J Exp Med 2000;191:129-138.

- 38 Diefenbach A, Jensen ER, Jamieson AM, Raulet DH: Rael and H60 ligands of the NKG2D receptor stimulate tumour immunity. Nature 2001;413:165-171.

39 Menon AG, Morreau H, Tollenaar RA, Alphenaar E, Van Puijenbroek M, Putter H, Janssen-Van Rhijn CM, Van De Velde CJ, Fleuren GJ, Kuppen PJ: Down-regulation of HLA-A expression correlates with a better prognosis in colorectal cancer patients. Lab Invest 2002;82:1725-1733.

40 Frey AB, Monu N: Signaling defects in antitumor T cells. Immunol Rev 2008;222:192205. 
-41 Konjevic G, Jurisic V, Spuzic I: Association of NK cell dysfunction with changes in LDH characteristics of peripheral blood lymphocytes (PBL) in breast cancer patients. Breast Cancer Res Treat 2001;66:255-263.

42 Hersey P, Edwards A, McCarthy WH: Tumour-related changes in natural killer cell activity in melanoma patients. Influence of stage of disease, tumour thickness and age of patients. Int J Cancer 1980;25:187-194.

-43 Sibbitt WL Jr, Bankhurst AD, Jumonville AJ, Saiki JH, Saiers JH, Doberneck RC: Defects in natural killer cell activity and interferon response in human lung carcinoma and malignant melanoma. Cancer Res 1984;44:852856.

44 Taketomi A, Shimada M, Shirabe K, Kajiyama K, Gion T, Sugimachi K: Natural killer cell activity in patients with hepatocellular carcinoma: a new prognostic indicator after hepatectomy. Cancer 1998;83:58-63.

45 Pierson BA, Miller JS: CD56+bright and CD56+dim natural killer cells in patients with chronic myelogenous leukemia progressively decrease in number, respond less to stimuli that recruit clonogenic natural killer cells, and exhibit decreased proliferation on a per cell basis. Blood 1996;88:22792287.

46 Tajima F, Kawatani T, Endo A, Kawasaki H: Natural killer cell activity and cytokine production as prognostic factors in adult acute leukemia. Leukemia 1996;10:478-482.

-47 Costello RT, Sivori S, Marcenaro E, LafagePochitaloff M, Mozziconacci MJ, Reviron D, Gastaut JA, Pende D, Olive D, Moretta A: Defective expression and function of natural killer cell-triggering receptors in patients with acute myeloid leukemia. Blood 2002;99: 3661-3667.

-48 Vaquer S, Jorda J, Lopez de la Osa E, Alvarez de los Heros J, Lopez-Garcia N, Alvarez de Mon M: Clinical implications of natural killer (NK) cytotoxicity in patients with squamous cell carcinoma of the uterine cervix. Gynecol Oncol 1990;36:90-92.

-49 Richards JO, Chang X, Blaser BW, Caligiuri MA, Zheng P, Liu Y: Tumor growth impedes natural-killer-cell maturation in the bone marrow. Blood 2006; 108:246-252.

- 50 Brenner CD, King S, Przewoznik M, Wolters I, Adam C, Bornkamm GW, Busch DH, Rocken M, Mocikat R: Requirements for control of B-cell lymphoma by NK cells. Eur J Immunol 2010;40:494-504.

- 51 Lai P, Rabinowich H, Crowley-Nowick PA, Bell MC, Mantovani G, Whiteside TL: Alterations in expression and function of signaltransducing proteins in tumor-associated $t$ and natural killer cells in patients with ovarian carcinoma. Clin Cancer Res 1996;2:161173 .
52 Rabinowich H, Suminami Y, Reichert TE, Crowley-Nowick P, Bell M, Edwards R, Whiteside TL: Expression of cytokine genes or proteins and signaling molecules in lymphocytes associated with human ovarian carcinoma. Int J Cancer 1996;68:276-284.

53 Smyth MJ, Swann J, Kelly JM, Cretney E, Yokoyama WM, Diefenbach A, Sayers TJ, Hayakawa Y: NKG2D recognition and perforin effector function mediate effective cytokine immunotherapy of cancer. J Exp Med 2004; 200:1325-1335.

54 Nausch N, Cerwenka A: NKG2D ligands in tumor immunity. Oncogene 2008;27:59445958.

55 Raulet DH, Guerra N: Oncogenic stress sensed by the immune system: role of natural killer cell receptors. Nat Rev Immunol 2009; 9:568-580.

56 Soriani A, Zingoni A, Cerboni C, Iannitto ML, Ricciardi MR, Di Gialleonardo V, Cippitelli M, Fionda C, Petrucci MT, Guarini A, Foa R, Santoni A: ATM-ATR-dependent upregulation of DNAM-1 and NKG2D ligands on multiple myeloma cells by therapeutic agents results in enhanced NK-cell susceptibility and is associated with a senescent phenotype. Blood 2009;113:3503-3511.

-57 Bryceson YT, March ME, Ljunggren HG, Long EO: Synergy among receptors on resting NK cells for the activation of natural cytotoxicity and cytokine secretion. Blood 2006;107:159-166.

58 Pogge von Strandmann E, Simhadri VR, von Tresckow B, Sasse S, Reiners KS, Hansen HP, Rothe A, Boll B, Simhadri VL, Borchmann P, McKinnon PJ, Hallek M, Engert A: Human leukocyte antigen-B-associated transcript 3 is released from tumor cells and engages the NKp30 receptor on natural killer cells. Immunity 2007;27:965-974.

59 Brandt CS, Baratin M, Yi EC, Kennedy J, Gao Z, Fox B, Haldeman B, Ostrander CD, Kaifu T, Chabannon C, Moretta A, West R, Xu W, Vivier E, Levin SD: The B7 family member B7-H6 is a tumor cell ligand for the activating natural killer cell receptor $\mathrm{NKp} 30 \mathrm{in} \mathrm{hu-}$ mans. J Exp Med 2009;206:1495-1503.

60 Le Maux Chansac B, Moretta A, Vergnon I, Opolon P, Lecluse Y, Grunenwald D, Kubin M, Soria JC, Chouaib S, Mami-Chouaib F: NK cells infiltrating a MHC class I-deficient lung adenocarcinoma display impaired cytotoxic activity toward autologous tumor cells associated with altered NK cell-triggering receptors. J Immunol 2005; 175:57905798.

61 Balsamo M, Scordamaglia F, Pietra G, Manzini C, Cantoni C, Boitano M, Queirolo $\mathrm{P}$, Vermi W, Facchetti F, Moretta A, Moretta L, Mingari MC, Vitale M: Melanoma-associated fibroblasts modulate NK cell phenotype and antitumor cytotoxicity. Proc Natl Acad Sci USA 2009; 106:20847-20852.
62 Coudert JD, Scarpellino L, Gros F, Vivier E, Held W: Sustained NKG2D engagement induces cross-tolerance of multiple distinct NK cell activation pathways. Blood 2008;111: 3571-3578.

63 Carlsten M, Baumann BC, Simonsson M, Jadersten M, Forsblom AM, Hammarstedt C, Bryceson YT, Ljunggren HG, HellstromLindberg E, Malmberg KJ: Reduced DNAM1 expression on bone marrow NK cells associated with impaired killing of CD34+ blasts in myelodysplastic syndrome. Leukemia 2010;24:1607-1616.

64 Groh V, Wu J, Yee C, Spies T: Tumour-derived soluble MIC ligands impair expression of NKG2D and T-cell activation. Nature 2002;419:734-738.

65 Salih HR, Rammensee HG, Steinle A: Cutting edge: Down-regulation of MICA on human tumors by proteolytic shedding. J Immunol 2002;169:4098-4102.

-66 Paschen A, Sucker A, Hill B, Moll I, Zapatka M, Nguyen XD, Sim GC, Gutmann I, Hassel J, Becker JC, Steinle A, Schadendorf D, Ugurel S: Differential clinical significance of individual NKG2D ligands in melanoma: soluble ULBP2 as an indicator of poor prognosis superior to S100B. Clin Cancer Res 2009; 15:5208-5215.

67 Castriconi R, Cantoni C, Della Chiesa M, Vitale M, Marcenaro E, Conte R, Biassoni R, Bottino C, Moretta L, Moretta A: Transforming growth factor beta 1 inhibits expression of NKp30 and NKG2D receptors: consequences for the NK-mediated killing of dendritic cells. Proc Natl Acad Sci USA 2003; 100:4120-4125.

68 Della Chiesa M, Carlomagno S, Frumento G, Balsamo M, Cantoni C, Conte R, Moretta L, Moretta A, Vitale M: The tryptophan catabolite L-kynurenine inhibits the surface expression of nkp46- and nkg2d-activating receptors and regulates NK-cell function. Blood 2006;108:4118-4125.

69 Bell D, Chomarat P, Broyles D, Netto G, Harb GM, Lebecque S, Valladeau J, Davoust J, Palucka KA, Banchereau J: In breast carcinoma tissue, immature dendritic cells reside within the tumor, whereas mature dendritic cells are located in peritumoral areas. J Exp Med 1999;190:1417-1426.

70 Moretta L, Ferlazzo G, Bottino C, Vitale M, Pende D, Mingari MC, Moretta A: Effector and regulatory events during natural killerdendritic cell interactions. Immunol Rev 2006;214:219-228.

-71 Solinas G, Germano G, Mantovani A, Allavena P: Tumor-associated macrophages (TAM) as major players of the cancer-related inflammation. J Leukoc Biol 2009;86:10651073.

72 Gabrilovich DI, Nagaraj S: Myeloid-derived suppressor cells as regulators of the immune system. Nat Rev Immunol 2009;9:162-174. 
73 Li H, Han Y, Guo Q, Zhang M, Cao X: Cancer-expanded myeloid-derived suppressor cells induce anergy of NK cells through membrane-bound TGF-beta 1. J Immunol 2009;182:240-249.

74 Nausch N, Galani IE, Schlecker E, Cerwenka A: Mononuclear myeloid-derived 'suppressor' cells express RAE-1 and activate natural killer cells. Blood 2008;112:4080-4089.

75 Smyth MJ, Teng MW, Swann J, Kyparissoudis K, Godfrey DI, Hayakawa Y: CD4+CD25+ T regulatory cells suppress NK cell-mediated immunotherapy of cancer. J Immunol 2006; 176:1582-1587.

76 Ghiringhelli F, Menard C, Terme M, Flament C, Taieb J, Chaput N, Puig PE, Novault S, Escudier B, Vivier E, Lecesne A, Robert C, Blay JY, Bernard J, Caillat-Zucman S, Freitas A, Tursz T, Wagner-Ballon O, Capron C, Vainchencker W, Martin F, Zitvogel L: $\mathrm{CD} 4+\mathrm{CD} 25+$ regulatory T cells inhibit natural killer cell functions in a transforming growth factor-beta-dependent manner. J Exp Med 2005;202:1075-1085.
77 Loeffler DA, Juneau PL, Heppner GH: Natural killer-cell activity under conditions reflective of tumor micro-environment. Int J Cancer 1991;48:895-899.

78 Flavell RA, Sanjabi S, Wrzesinski SH, Licona-Limon P: The polarization of immune cells in the tumour environment by TGFbeta. Nat Rev Immunol 2010;10:554-567.

79 Moore KW, de Waal Malefyt R, Coffman RL, O'Garra A: Interleukin-10 and the interleukin-10 receptor. Annu Rev Immunol 2001; 19:683-765.
80 Kundu N, Beaty TL, Jackson MJ, Fulton AM: Antimetastatic and antitumor activities of interleukin 10 in a murine model of breast cancer. J Natl Cancer Inst 1996;88:536-541.

81 Campoli M, Ferrone S: Tumor escape mechanisms: potential role of soluble HLA antigens and NK cells activating ligands. Tissue Antigens 2008;72:321-334.

82 Rouas-Freiss N, Moreau P, Menier C, LeMaoult J, Carosella ED: Expression of tolerogenic HLA-G molecules in cancer prevents antitumor responses. Semin Cancer Biol 2007;17:413-421.

-83 Rajagopalan S, Bryceson YT, Kuppusamy SP, Geraghty DE, van der Meer A, Joosten I, Long EO: Activation of NK cells by an endocytosed receptor for soluble HLA-G. PLoS Biol 2006;4:e9.

84 Favier B, Lemaoult J, Lesport E, Carosella ED: ILT2/HLA-G interaction impairs NKcell functions through the inhibition of the late but not the early events of the NK-cell activating synapse. FASEB J 2010;24:689699 